ISSN e- 2594-1100

en-claves del pensamiento / núm. 31 / enero-junio / 2022 / e499

https://doi.org/10.46530/ecdp.v0i31.499 DOSSIER

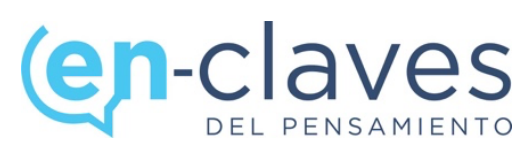

\title{
VULNERABILIDAD, OPRESIÓN E INJUSTICIA SOCIAL: EL CASO DE LA DIVERSIDAD FUNCIONAL DESDE LA PERSPECTIVA DE IRIS MARION YOUNG
}

\author{
Vulnerability, Oppression, and Social Injustice: The Case of Functional Diversity \\ from the Perspective of Iris Marion Young
}

\author{
Marta Mira-Aladrén, Universidad de Zaragoza \\ Correo electrónico: mmira@unizar.es \\ Raquel Lozano-Blasco, Universidad de Zaragoza \\ Correo electrónico: rlozano@unizar.es
}

Recibido: $15 / 05 / 2021$

Aceptado: 15/11/2021

Publicado: 07/01/2022

\begin{abstract}
Resumen. La teoría de Iris Marion Young critica la definición de justicia social en términos únicamente distributivos, apostando por una concepción que contemple el reconocimiento. Para ello, se apoya en conceptos como grupo social, opresión, espacio público y una crítica al ideal de imparcialidad. A partir de esta visión, este trabajo pretende dar respuesta a diferentes preguntas en relación con la situación de vulnerabilidad, opresión e injusticia social que viven las personas en situación de discapacidad. Se aportan visiones desde la filosofía y desde la psicología social que permitan comprender qué es la injusticia en términos de reconocimiento, cómo se reproduce, cómo afecta a la diversidad funcional y cómo combatirla. Todo ello, da como resultado una reflexión que sirve de base para el replanteamiento de propuestas como la de Nussbaum, que van más allá de las propuestas o modificaciones formales, basándose en la relevancia del espacio público y las relaciones informales.
\end{abstract}

Palabras clave: discapacidad, diversidad funcional, justicia social, opresión, discriminación.

Abstract. Iris Marion Young's theory criticises the definition of social justice in purely distributive terms, in favour of a conception that includes recognition. To this end, she relies on concepts such as social group, oppression, public space and a critique of the ideal of impartiality. Based on this vision, this work aims to answer different questions in relation to the situation of vulnerability, oppression and social injustice experienced by people with disabilities. Visions are provided from philosophy and social psychology that allow us to understand what injustice is in terms of recognition, how it is reproduced, how it affects functional diversity and how to combat it. All of this results in a reflection that serves as a basis for rethinking proposals such as Nussbaum's, which go beyond formal proposals or modifications, based on the relevance of public space and informal relationships.

Keywords: Disability, functional diversity, social justice, oppression, discrimination.

Cómo citar: Mira-Aladrén, M., y Lozano-Blasco, R. (2022). Vulnerabilidad, opresión e injusticia social: el caso de la diversidad funcional desde la perspectiva de Iris Marion Young. EN-CLAVES del pensamiento, 0(31), e499. doi: https://doi.org/10.46530/ecdp.v0i31.499

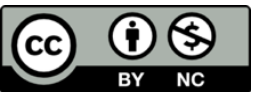

Esta obra está protegida bajo una Licencia

Creative Commons Atribución - No comercial

4.0 Internacional 


\section{Introducción*}

Subnormales, deficientes, minusválidos o discapacitados, son algunos de los adjetivos con los que se han referido las sociedades a las personas en situación de discapacidad a lo largo de la historia. Atendiendo a su etimología, no pasa desapercibido el sentido peyorativo de estas palabras, por debajo de lo normal, menos eficientes, menos válidos, sin capacidad. Todos ellos, dan una perspectiva histórica de la visión cultural de la discapacidad en la sociedad.

Esta imagen se ha transmitido de diferentes modos hasta nuestro tiempo. Actualmente, el movimiento de la discapacidad ha reivindicado nuevos conceptos como el de la diversidad funcional para acabar con esa valoración negativa. Además, desde el ámbito formal, se han fomentado medidas para terminar con la vulneración de derechos de estas personas y protegerlos frente a posibles discriminaciones, como la Convención Internacional de las Personas con Discapacidad de la ONU.

Pese a estos esfuerzos, son muchos los testimonios y estudios que plantean que todavía existe una discriminación y una imagen de infravaloración de las personas en situación de discapacidad que afectan a su participación en la sociedad. Todo ello, supone situaciones que Iris Marion Young denominaría de opresión y, por tanto, de injusticia social debida a una falta de reconocimiento.

Con todo ello surgen preguntas como, ¿cómo detectar las situaciones de injusticia? ¿Cómo se reproducen estas imágenes culturales acerca de la discapacidad? ¿Está la diversidad funcional en una situación de injusticia? Y, si es así, ¿cómo podemos combatirla? Este trabajo tratará de dar respuesta a las mismas a través del pensamiento crítico acerca de la participación democrática de la autora contemporánea Iris Marion Young.

\section{¿Qué es la injusticia social?}

La justicia social ha sido definida desde diferentes perspectivas, algunas, más próximas al pensamiento marxista, más centradas en la redistribución, y, otras, reivindicadas desde

\footnotetext{
* Notas previas de este tema se presentaron como trabajo de fin de grado "La escucha en la democracia comunicativa de Iris Young", realizado en la Universidad de Zaragoza por Marta Mira-Aladrén y bajo la dirección de Ma. Aránzazu Hernández Piñeiro. Disponible en https://zaguan.unizar.es/record/31924/files/TAZ-TFG-2015-2102.pdf.
} 
movimientos vinculados al reconocimiento de determinados grupos sociales, como puede ser el feminismo o los movimientos indígenas o por los derechos civiles en Estados Unidos. En este caso, nos centramos en esta segunda concepción. Ante la pregunta ¿qué puede entenderse por justicia social? Young realiza toda una teoría recogida en diferentes obras. La autora plantea: "La justicia no debería referirse sólo a la distribución, sino también a las condiciones institucionales necesarias para el desarrollo y ejercicio de las capacidades individuales, de la comunicación colectiva y de la cooperación". ${ }^{1}$

Desde esta perspectiva parte tanto su definición de justicia social como la reproducción de determinados procesos sociales que reproducen la opresión y la falta de reconocimiento de determinados grupos sociales. En este sentido, puede considerarse que la distribución de bienes no es suficiente para lograr una justicia social, dado que existen múltiples relaciones sociales más allá de la económica. Ejemplos de esta definición estarían en los movimientos feminista, negro, indígena y de liberación gay y lésbica, en los que se basa la autora.

De acuerdo a este planteamiento, para comprender las injusticias, eliminarlas y/o repararlas, éstas se deben repensar desde la noción de grupo social en función del concepto de opresión que, según Young "se refiere a las grandes y profundas injusticias que sufren algunos grupos como consecuencia de presupuestos y reacciones a menudo inconscientes de gente que en las interacciones corrientes tiene buenas intenciones, y como consecuencia también de los estereotipos difundidos [...] de los procesos normales de la vida cotidiana". ${ }^{2}$

En este sentido, la opresión hace referencia a un concepto estructural y hace referencia a las barreras institucionales para poder participar en las condiciones de vida, determinación de las acciones y la autodeterminación. Además, se encontraría sostenido por procesos institucionales y culturales no cuestionados, llegando a ser, como definiremos más adelante, una reproducción inconsciente de estereotipos o prejuicios socialmente aceptados.

A partir de estos planteamientos, se propone una redefinición de la justicia en términos de dominación y opresión. Para su desarrollo, la autora define lo que ella denomina como las "cinco caras de la opresión"3 que favorecerían el reconocimiento y

\footnotetext{
${ }^{1}$ Iris, M. Young, La justicia y la política de la diferencia (Madrid: Cátedra, 2000), 71.

${ }^{2}$ Ibid., 75.

${ }^{3}$ Ibid., 86.
} 
análisis de estas injusticias estructurales. Estos criterios son: explotación, marginación, carencia de poder, imperialismo cultural y violencia.

En primer lugar, la explotación. Young complejiza el concepto marxiano, sobrepasando el concepto de clase, para atender también al trabajo no asalariado, fundamentalmente, generizado y racializado. Es decir, se trataría de la apropiación de los resultados de trabajo, de un grupo social a otro. Un ejemplo sería el trabajo doméstico y de cuidados realizado mayoritariamente por mujeres, pero socialmente no reconocido como trabajo. ${ }^{4}$ Aún más, esta cara de la opresión consiste en la desigual producción y distribución económica, sino también en determinadas relaciones sociales de poder en sentido amplio.

Con respecto a la segunda cara, se define a las personas marginales como "aquéllas a las que el sistema de trabajo no puede o no quiere usar". ${ }^{5}$ Estas personas no pueden acceder a bienes materiales, por lo que precisan de políticas redistributivas de intervención estatal para paliar su opresión, generando una dependencia institucional. Según Young, ${ }^{6}$ esta opresión se daría en dos vertientes: por un lado, la privación de derechos y libertades; y, por el otro, el bloqueo de las oportunidades para ejercer sus capacidades, siendo socialmente reconocidos. En este sentido, es una cuestión cultural vinculada al ideal social de autonomía, teniendo efectos en la autoestima y bienestar psicosocial de las personas marginadas.

La tercera cara es denominada carencia de poder. ${ }^{7}$ Con ella hace referencia a la no participación de la mayoría de la población en la toma de decisiones que afectan a su vida. Se vincula a la carencia de estatus de privilegio profesional, lo que generaría dificultades para expresarse y para que sus opiniones generen respeto. Para las personas oprimidas por este medio, no existe ni autonomía laboral ni oportunidad para la creatividad y la autodeterminación.

Para Young, ${ }^{8}$ otra opresión es el imperialismo cultural, estrechamente vinculado al concepto de grupo social. Se trataría de la "universalización de la experiencia y la cultura de un grupo dominante, y su imposición como norma". ${ }^{9}$ Ello generaría una representación

\footnotetext{
${ }^{4}$ Ibidem.

${ }^{5}$ Ibid., 94.

${ }^{6}$ Ibidem.

${ }^{7}$ Ibidem.

${ }^{8}$ Ibidem.

${ }^{9}$ Ibid., 103.
} 
errónea de la humanidad, definida exclusivamente en función de las experiencias y cultura del grupo dominante. Mediante mecanismos de poder ligados a las vías de interpretación y comunicación social, se convierte al resto de grupos sociales en otros. Es decir, en desviaciones inferiores, en negación y carencia, sin cuestionamiento y naturalizando esas creencias. La paradoja se produce cuando al ser visibilizados los grupos oprimidos se convierten en grupos estereotipados y marginalizados.

Por último, la violencia. Young ${ }^{10}$ entiende que no se trata de una acción individual, sino de una práctica social. Ésta produce que el hecho de pertenecer a un grupo social determinado, sea una predisposición a ser víctima. "En la medida en que las instituciones y las prácticas sociales alientan, toleran o permiten que se lleve a cabo la violencia contra miembros de grupos determinados, dichas instituciones y prácticas son injustas y deberían reformarse". ${ }^{11}$

Atendiendo a estas definiciones de opresión y grupo social, vinculadas con el concepto de injusticia social, se entiende que, en tanto en cuanto, las personas pertenecen a diversos grupos sociales (ej. mujer, lesbiana, con discapacidad, etc.), las opresiones pueden darse "interseccionadas". ${ }^{2}$ Además, los grupos no son todos oprimidos igualmente, comparten una condición común, que sufren de diferente manera. Es decir, tienen en común el hecho de sufrir injusticias más allá de la redistribución, pese a que lo hagan de diferente manera. Convirtiendo la opresión en "una condición de grupos"13 relacional. En definitiva, un grupo social sería el resultado de cómo se ven a sí mismas y como entienden a las demás.

Por tanto, "un grupo social es un colectivo de personas que se diferencia de al menos otro grupo a través de formas culturales, prácticas o modos de vida". ${ }^{14}$ Lo que caracteriza a esta propuesta es, por un lado, que no se trata de algo esencialista, sino que surge de las interrelaciones entre sujetos, grupos, etcétera. Y, por otro lado, que la disolución de los grupos no conlleva una eliminación de la opresión, sino que las diferencias de grupo son un fenómeno inevitable, e incluso deseable.

\footnotetext{
${ }^{10}$ Ibidem.

${ }^{11}$ Ibid., 110.

${ }^{12}$ Ma. José Guerra Palmero, "Presentación. Iris Marion Young, la pensadora de las injusticias estructurales y de la responsabilidad política", Enrahonar. Quaderns de Filosofía, núm. 51 (2013): 5-12. http://revistes.uab.cat/enrahonar/article/view/v51-guerra/pdf-es.

${ }^{13}$ Young, La justicia y la política de la diferencia, 73.

${ }^{14}$ Ibid., 77.
} 
En definitiva, el concepto de grupo social y pertenencia se basa en las relaciones entre grupos, entre los grupos y las instituciones, se trata de un problema relacional que varía en función de los grupos comparados. La opresión, vendría por una concepción errónea del sujeto y, por tanto, del grupo social, basada en un individualismo esencialista, vinculada a grupos sociales dominantes, cuya percepción se entiende como más válida que la del resto de grupos, incluso como universal, sometiendo a otros grupos a su percepción. Por ello, para lograr la justicia social, para Young, ${ }^{15}$ es precisa una concepción de sujeto, más abierta y heterogénea. Entendiendo que cada sujeto tiene experiencias diferentes, vinculadas en gran medida a su percepción en función del grupo social al que pertenecen.

\section{¿Cómo se reproduce la injusticia?}

La diversidad funcional ha tenido diferentes concepciones a lo largo de la historia. En nuestra cultura occidental y judeo-cristiana, nace de la concepción de que la enfermedad es un castigo divino. ${ }^{16}$ Aún hoy en día, nuestra cultura occidental - democrática, mantiene prejuicios y refuerza la discriminación hacia las personas con diversidad funcional—. ${ }^{17}$

La vivencia de la diferencia parte de unas raíces culturales ${ }^{18}$ que inequívocamente influyen en la percepción de forma que no es algo individual y personal sino una muestra del simbolismo de la sociedad, que ha sido generado mediante normas sociales implícitas. ${ }^{19}$

Aunque nuestra sociedad occidental presume de su democracia, humanismo y tolerancia, la evidencia científica muestra como las acciones sociales son profundamente segregadoras. ${ }^{20}$ En otras palabras, se ejecutan acciones en las que se categoriza a las personas según unos estándares de jerarquización y exclusión las encontramos día sí y día también. De este modo construyen la noción de personas vulnerables, que deben ser

\footnotetext{
${ }^{15}$ Ibidem.

${ }^{16}$ Patricia M. Ruíz Quiroga, "La evolución de la atención a la diversidad del alumnado de educación primaria a lo largo de la historia”, Temas para la Educación, Revista Digital para Profesionales de la Enseñanza, núm. 8 (2010): 1-15, https://feandalucia.ccoo.es/docu/p5sd7241.pdf.

${ }^{17}$ Begoña Abad Miguélez, "La producción socio-institucional de sufrimiento social", RIMCIS - International and Multidisciplinary Journal of Social Sciences 5, núm. 1 (2016): 1-25. http://doi.org/10.17583/rimcis.2016.1802.

18 Antonio Madrid, La política y la justicia del sufrimiento (Madrid: Trotta, 2010).

${ }^{19}$ David Le Breton, Sociología del cuerpo (Buenos Aires: Ed. Nueva Visión, 2008).

${ }^{20}$ Jordi Solé Blanch y Asun Pié Balaguer (coords.), Politicas del sufrimiento y la vulnerabilidad. Madrid: Icaria, 2018.
} 
"cuidadas" mientras "se vela" por su propio bien, realizando grupos excluyentes entre sí. ${ }^{21}$ Esta comparación nosotros (endogrupo) frente ellos (exogrupos), acaba generando un rechazo entre grupos, de forma que mediante la actitud se establecen estereotipos (creencias aceptadas por el grupo), prejuicios (evaluaciones negativas) y finalmente la discriminación (conductas no prosociales). ${ }^{22}$

En este proceso tanto los prejuicios sociales como los estereotipos sobre la diversidad funcional muestran como es la sociedad quien genera al tipo de individuo que más le conviene en razón de determinantes políticos y económicos. ${ }^{23}$ En este punto, es necesario plantear cómo los prejuicios de la diversidad se vinculan a la lástima, impidiendo el desarrollo potencial de la persona. ${ }^{24} \mathrm{Y}$ a la no aceptación de la diversidad funcional como un elemento intrínsecamente natural y la no determinación de una conducta puramente humana como es la empatía. Si bien, el conocimiento, el contacto y el diálogo, controlados, rompen esta percepción segregada favoreciendo una visión más inclusiva. ${ }^{25}$

En este punto, encontramos como es el pensamiento médico en términos de biopoder, ${ }^{26}$ quien esclarece la distinción entre lo normal y aceptable para la sociedad del resto. La composición de este poder sobre los cuerpos no mana de un sujeto concreto, no existe un villano culpable que envenena al resto haciéndoles creer normales frente a otros. El poder está lejos de ser una sustancia transportada de una mano a otra, tal y como expondrían los postulados marxistas. Es más bien, un entramado de expertos que dictan la verdad, y que generan un discurso acorde a sus necesidades, ${ }^{27}$ cumpliendo con el prototipo de cuerpo determinado por la sociedad. ${ }^{28}$ Estas relaciones de poder modelan el pensamiento y bajo la subjetividad dictan lo correcto y deseable de lo incorrecto y no deseable. Estas visiones son impulsadas bajo el lema del experto, quienes acaban generando un discurso

\footnotetext{
${ }^{21}$ Henri Tajfel, "La catégorisation sociale", en Serge Moscovici (Ed.), Introduction à la psychologie sociale, vol. 1 (París: Larousse, 1972).

${ }^{22}$ Ibidem.

${ }^{23}$ John Shotter y Kenneth J. Gergen, Texts of identity (California: Sage Publications, 1989).

24 Anna M. Fernández, "Prejuicios y estereotipos. Refranes, chistes y acertijos, reproductores y transgresores", Revista de Antropología Experimental, núm. 11 (2011): 317-328. https://revistaselectronicas.ujaen.es/index.php/rae/article/view/1932.

25 Elizabeth Levy Paluck, Seth A. Green y Donald P. Green. "The contact hypothesis re-evaluated", Behavioural Public Policy, núm. 3.2 (2019): 129-158. http://dx.doi.org/10.2139/ssrn.2973474.

${ }^{26}$ Michel Foucault, El nacimiento de la clinica (Madrid: Siglo XXI, 2001).

${ }^{27} \mathrm{Ibid}$;; Solé y Pié, Políticas del sufrimiento.

${ }^{28}$ Shotter y Gergen, Texts of identity.
} 
acorde a la subjetividad de la sociedad. En otras palabras, el poder es una telaraña de relaciones sociales donde el grupo que la teje promulga su visión.

De este modo, se refuerza la discriminación, los estereotipos y los prejuicios en lugar de luchar por la "revolución de los cuerpos". ${ }^{29}$ Desde esta perspectiva, se debe comprender cómo las instituciones desde los hospitales a las escuelas no son organizaciones inocuas, sino que acaban siendo una representación de la sociedad que las ha generado. Esta situación exige de una profunda reflexión para los profesionales que trabajan en ellas, pues deben comprender como su propia visión puede ser juiciosa en lugar de empática y asertiva. ${ }^{30}$

En este sentido, la propia noción de vulnerabilidad presenta una fuerte dicotomía. ${ }^{31}$ En primera instancia implica la posibilidad de ser vulnerado de forma que se buscan las causas de dicha vulnerabilidad. Si bien, las causas de dicha vulnerabilidad se originan en la determinación de lo aceptable o normal del resto preestablecidas por el poder biomédico. ${ }^{32}$ De este modo, no se vela por el desarrollo pleno de la persona, sino que aún nos centramos en legitimar la diferencia, no como un hecho propio de la naturaleza humana, sino en el establecimiento de un nosotros frente a un ellos.

De esta forma, se genera una concepción de la identidad social, en la cual los seres humanos se categorizan en grupos excluyentes reforzando las diferencias y tejiendo su propia membresía. ${ }^{33}$ En otras palabras, el propio Estado que dicta que le cuida en su beneficio, es el mismo que le atribuye una categoría que le diferencia del resto. ${ }^{34}$ Es decir, la vulnerabilidad, los prejuicios, los estereotipos y la discriminación derivan de orden establecido por el poder biomédico. Así, se naturaliza esta expresión. La sociedad acepta como factor inherente la existencia de colectivos en riesgo de vulnerabilidad, ${ }^{35}$ sin pararse a reflexionar cómo es fruto de la clasificación de nosotros frente a ellos. En este sentido, una

\footnotetext{
${ }^{29}$ Tomás Sánchez Criado, Cuerpo, discapacidad, vejez: calles para todos (Barcelona: Material de la UOC, Introducción a las Ciencias Sociales, 2019).

${ }^{30}$ Ibidem.

${ }^{31}$ Ibidem.

${ }^{32}$ Ibidem.; Foucault, El nacimiento de la clínica.

33 Tajfel, "La catégorisation sociale".

34 Solé y Pié, Políticas del sufrimiento.

${ }^{35}$ Madrid, La política y la justicia del sufrimiento; Solé y Pié, Políticas del sufrimiento.
} 
persona dejará de ser vulnerable cuando haya medidas que lo permitan, cuando se la proteja, cuando se vea como parte intrínseca y necesaria de una sociedad inclusiva. ${ }^{36}$

En suma, es responsabilidad de la sociedad replantear y analizar de forma crítica el imaginario colectivo en el cual se mantienen las luchas constantes de endogrupos y exogrupos, donde se perfila tanto el cuerpo como la identidad humana que un ser debería tener, y donde se categoriza al ser humano. Es nuestra responsabilidad reflexionar de manera profunda acerca de los estereotipos, prejuicios y discriminación adquirida a lo largo de nuestra existencia, tomar conciencia de ella para poder decidir si verdaderamente queremos mantener esta posición o si preferimos apostar por la inclusión.

\section{¿Existe injusticia para las personas con diversidad funcional?}

De acuerdo con lo anterior, parece necesario analizar cómo se vincula esta discriminación con la injusticia en el caso de la diversidad funcional, atendiendo a su evolución, pasando de un modelo centrado en cuestiones médicas, el modelo médico, a otro fundamentado en cuestiones sociopolíticas, el modelo social. ${ }^{37}$

En los últimos decenios del siglo XX, se estableció una nueva visión menos naturalista de la discapacidad, basada en el modelo social. Este nuevo enfoque expresa que la discapacidad no es una cuestión individual, sino que encuentra sus dificultades en la forma en la que se organiza la sociedad. Busca maneras de eliminar las barreras que restringen las condiciones de vida de las personas con discapacidad, para que puedan ser independientes, autónomas e iguales en la sociedad, apostando por términos como el de diversidad funcional. ${ }^{38}$

Este nuevo enfoque rechaza el modelo médico, ya que considera la diversidad funcional como parte de la condición humana, un elemento que enriquece la sociedad y

\footnotetext{
${ }^{36}$ Ibid.; Junfei Lu, Wesley B. Webber, Devon Romero y Chris Chirinos, "Changing Attitudes Toward People with Disabilities Using Public Media: An Experimental Study”, Rehabilitation Counseling Bulletin 61, núm. 3 (2017). http://dx.doi.org/10.1177/0034355217700820.

37 Sophie Mitra y Tom Shakespeare, "Remodeling the ICF", Disability and health journal 12, núm. 3 (julio, 2019): 337-339. https://doi.org/10.1016/j.dhjo.2019.01.008; Manuel Aparicio, "Estigmatización, invisibilización y cosificación de las personas con diversidad funcional. Una aproximación desde la justicia como reconocimiento de Axel Honneth", Revista Española de Discapacidad 4, núm. I (2016): 177-190. https:/www.cedd.net/redis/index.php/redis/article/view/245; Fernando Pindado, Hacia una única catalogación de los derechos fundamentales -los derechos económicos, sociales y culturales de las personas con discapacidad como derechos fundamentales (Madrid: Ediciones Cinca, 2015).

${ }^{38}$ Pindado, Hacia una única catalogación.
} 
reivindica los derechos de estas personas. En conjunto, la novedad de este modelo consiste en poner de manifiesto que la discapacidad no es una cuestión patológica ligada al ámbito biológico, sino que debe ser interpretada, más bien, como una patología social, como una forma de opresión a la que se somete a las personas cuyos cuerpos funcionan de modo diferente al estadísticamente habitual. ${ }^{39}$ Un ejemplo de este nuevo paradigma es la aprobación de la Convención Sobre los Derechos de las Personas con Discapacidad de la ONU, basada en este modelo social. ${ }^{40}$

Pero, la pregunta sería ¿ha sido el planteamiento de este modelo y su configuración en la Convención Internacional suficiente para acabar con la injusticia sobre las personas con discapacidad? Para dar respuesta a estas cuestiones recurriremos a los datos presentados por el Observatorio Estatal de la Discapacidad (OED) de España, ${ }^{41}$ el Eurobarómetro 493 sobre la discriminación en la Unión Europea ${ }^{42}$ y algunas de las situaciones descritas por Aparicio, ${ }^{43}$ en relación con la teoría de Young.

En primer lugar, a nivel formal, se puede hablar de que en los últimos años ha disminuido la percepción de que la discriminación por discapacidad está extendida en su país, llegando a situarse en un 44 por ciento de la población encuestada. ${ }^{44}$ En cambio, esta condición sigue considerándose una desventaja o una situación de vulnerabilidad. El espacio público es en el que se percibe mayor discriminación. ${ }^{45} \mathrm{Y}$ se dan situaciones como un menor nivel de estudios, mayores tasas de abandono escolar, mayores tasas de paro y empleo en regímenes especiales. ${ }^{46}$ Además, en el caso de las personas con discapacidad intelectual, pese a tener un cupo de reserva formal del 2 por ciento en la oferta pública, se ha detectado una mayor dificultad para acceder al empleo público dada la falta de

\footnotetext{
${ }^{39}$ Mitra, "Remodeling the ICF"; Aparicio, "Estigmatización, invisibilización"; Pindado, Hacia una única catalogación.

${ }^{40}$ Mitra, "Remodeling the ICF"; Pindado, Hacia una única catalogación.

${ }^{41}$ Antonio Jiménez, Personas con discapacidad y discriminación múltiple en España: situación y propuestas (Madrid: Observatorio Estatal de la Discapacidad, 2017). https:/www.observatoriodeladiscapacidad.info/wpcontent/uploads/2017/12/DISCRIMINACION-MULTIPLE-OED.pdf.

42 European Commission, Special Eurobarometer 493: Discrimination in the EU (including LGBTI)

(Bruselas: Directorate-General for Communication, 2019).

http://data.europa.eu/euodp/en/data/dataset/S2251_91_4_493_ENG.

43 Aparicio, "Estigmatización, invisibilización".

${ }^{44}$ European Commission, Special Eurobarometer 493...

${ }^{45}$ Ibid., 493.

${ }^{46}$ Jiménez, Personas con discapacidad.
} 
legislación accesible o las dificultades burocráticas, entre otras. ${ }^{47}$ Con todo ello parece que, pese a la valoración positiva de las medidas desarrolladas por España, ${ }^{48}$ la discriminación por discapacidad continúa siendo una realidad.

De acuerdo con la teoría de Young, presentada anteriormente, puede afirmarse que existe una opresión en diferentes caras, atendiendo únicamente a estos datos. En primer lugar, explotación, en referencia a los regímenes especiales que ocupan estas personas y que cuentan con una menor dotación económica. En segundo lugar, marginación, desde el sistema educativo que, a la vista del abandono escolar no cumple con sus necesidades y demandas, o desde el ámbito laboral en el que hay mayores tasas de paro. En tercer lugar, carencia de poder, en tanto en cuanto, estas personas no tienen acceso a un determinado nivel de estudios o puestos de trabajo que otorgan un estatus superior, negando su acceso, incluso a la legislación y, por tanto, a sus derechos, al no estar en formato accesible. En cuarto lugar, imperialismo cultural, vinculado a la imposición de un modelo educativo y laboral generalizado, o de un laberinto burocrático de difícil comprensión para poder hacer efectivos sus derechos. Por último, violencia, en relación a la percepción de discriminación en el espacio público, y a la violencia institucional asociada a la falta de accesibilidad o la burocracia.

En relación con esta opresión y, especialmente con la última de sus caras, conviene hacer referencia a las diferentes formas de discriminación y violencia a las que se enfrentan las personas con discapacidad en su día a día. Un autor que ha analizado esta situación desde visiones próximas a las de la teoría de la justicia social Aparicio, ${ }^{49}$ quien tomó como referencia la de Axel Honneth. En su texto habla de tres fenómenos injustos que sufren las personas con discapacidad: estigmatización, invisibilización y cosificación.

En primer lugar, la estigmatización, basada en la reproducción de la injusticia comentada en el apartado anterior, creando una imagen desvalorizada de la diversidad funcional. Se caracterizaría, como se ha comentado anteriormente, por una perspectiva de lástima, no adaptación a la normalidad o incapacidad. Todo ello, desde el uso de prejuicios y estereotipos, basados en una naturalización de los mismos. De este modo, se

\footnotetext{
${ }^{47}$ Silvia Muñoz (coord.), Cuadernos de Buenas Prácticas. Las personas con discapacidad intelectual en la función pública: Informe sobre situación, recomendaciones y apoyos tecnológicos (Madrid: Plena Inclusión, 2018). https://www.plenainclusion.org/publicaciones/buscador/las-personas-con-discapacidad-intelectual-enla-funcion-publica-informe-sobre-situacion-recomendaciones-y-apoyos-tecnologicos/.

${ }^{48}$ European Commission, Special Eurobarometer, 493.

${ }^{49}$ Aparicio, "Estigmatización, invisibilización".
} 
desencadenaría un malestar en las personas con discapacidad, así como una exclusión social basada en su situación. ${ }^{50}$ Atendiendo a las características de este fenómeno, de acuerdo con la teoría de la justicia social de Young, podríamos afirmar que se está generando opresión, en sus facetas de: imperialismo cultural ${ }^{51}$, dadas la delimitación de estándares o normas sociales de las que se excluye a las personas con discapacidad; y, marginación, dado que se entiende que "sistema de trabajo no puede o no quiere usar" 52 a estas personas.

Otra de las patologías sociales que Aparicio, ${ }^{53}$ tomando a Honneth, menciona es el de la cosificación, estrechamente vinculado al anterior, y que se centra en el no reconocimiento de este grupo social como personas, sino como cosas. En este caso se produce un cambio en la relación con las personas al adquirir la condición de discapacidad, centrándose en ésta y no en la propia persona. Un ejemplo significativo en este caso sería el de los y las profesionales que trabajan en el sector de los cuidados que pueden terminar automatizando ese trabajo, olvidando que a quien están proveyendo de cuidados es una persona. En este sentido, se pierde la empatía y la capacidad de crear una conexión social con las personas, eliminando su participación en la misma. ${ }^{54}$ De acuerdo a esta situación, se podría decir que, tendríamos un ejemplo claro de carencia de poder, ${ }^{55}$ al negar la participación de estas personas en las decisiones sobre sus cuidados. Así como, de imperialismo cultural, marginación e incluso violencia, ${ }^{56}$ al negar la capacidad de estas personas, como tales, considerándose como cosas.

Por último, en la relación de Aparicio ${ }^{57}$ encontramos la invisibilización, vinculada con la negación total de reconocimiento, anulando su presencia física. Un ejemplo de ello, aplicado al caso de la diversidad funcional, es el no comunicarse directamente con la persona con discapacidad, si no con su acompañante, cuidadora o familiar, negándoles tanto el reconocimiento como la participación e, incluso, su existencia. De forma similar al caso de la cosificación, estaríamos ante un caso de opresión, en prácticamente la totalidad

\footnotetext{
${ }^{50}$ Ibid.; Fernández, "Prejuicios y estereotipos".

${ }^{51}$ Young, La justicia y la política de la diferencia.

${ }^{52}$ Ibid., 94.

${ }^{53}$ Aparicio, "Estigmatización, invisibilización".

${ }^{54}$ Ibidem.; Sánchez, Cuerpo, discapacidad, vejez.

${ }^{55}$ Young, La justicia y la política de la diferencia.

${ }^{56}$ Ibidem.

${ }^{57}$ Aparicio, "Estigmatización, invisibilización”.
} 
de sus caras, salvo la explotación, suponiendo una injusticia social, en términos de reconocimiento. ${ }^{58}$

Todas estas situaciones, pueden verse interseccionadas por la pertenencia a varios grupos sociales. ${ }^{59}$ Concretamente, en el caso de la diversidad funcional el Informe del $\mathrm{OED}^{60}$ señala grupos como el de las mujeres, la juventud (de 16 a 29 años), la población con discapacidad que entra en procesos de envejecimiento para el mercado laboral (de 45 a 64) o las personas migrantes (especialmente de países de fuera de la Unión Europea). En estos casos, se puede observar la necesidad de vincular la opresión en espacios informales con la intervención y, en muchos casos opresión, desde las instituciones. Siendo el caso de las personas migrantes el más ejemplificante. Además, no debe olvidarse que estas relaciones suponen a su vez un detrimento del nivel educativo o de la posibilidad de acceder a una vivienda digna y con las necesidades de accesibilidad cubiertas.

Con todo lo anterior, puede corroborarse que, pese a los esfuerzos a nivel formal que parecen haberse realizado, o que se percibe que se han realizado, todavía persiste una situación de injusticia social para las personas con discapacidad. Concretamente, en el ámbito del espacio informal, aunque no se debe olvidar que este espacio está estrechamente vinculado a las actitudes y creencias que se mantienen desde las instituciones, las cuales también pueden ejercer violencia y, por tanto, opresión e injusticia. ${ }^{61}$ Un ejemplo es la falta de acceso a legislaciones y, en consecuencia, a derechos como el empleo. ${ }^{62}$

\section{¿Cómo combatir la injusticia?}

Este último apartado busca adentrarse en las soluciones para combatir las injusticias que se han planteado anteriormente desde la perspectiva teórica de Young y su vinculación con la propuesta de Nussbaum. ${ }^{63}$ Esta última propuesta por Aparicio ${ }^{64}$ en referencia al caso de la diversidad funcional. Para ello, se tomará como referencia la propuesta de la última de las

\footnotetext{
${ }^{58}$ Young, La justicia y la política de la diferencia.

${ }^{59}$ Ibidem.

${ }^{60}$ Jiménez, Personas con discapacidad.

${ }^{61}$ Young, La justicia y la política de la diferencia.

${ }^{62}$ Muñoz (coord.), Cuadernos de buenas prácticas.

${ }^{63}$ Martha C. Nussbaum, El ocultamiento de lo humano: repugnancia, vergüenza y ley (Madrid: Katz Barpal, 2006).

${ }^{64}$ Aparicio, "Estigmatización, invisibilización".
} 
autoras, que se sostiene sobre tres ejes fundamentales: legislación que combata la humillación pública y la discriminación; rediseño de los espacios públicos; e, implementación de prácticas informales de educación moral y de debate social que cuestionen el mito de la perfección. ${ }^{65} \mathrm{Si}$ se analizan estas propuestas, se observan grandes paralelismos entre ambas. El primero de ellos en la crítica al ideal de imparcialidad y de negación de la(s) diferencia(s) que propone Young, ${ }^{66}$ con respecto al mito de la perfección del ciudadano de Nussbaum. ${ }^{67} \mathrm{Y}$, en segundo lugar, en relación con la necesidad de rediseñar el espacio público y de debate social, incluyendo en ellas a cualquier grupo.

Para ello, Young ${ }^{68}$ apuesta por la democracia comunicativa para eliminar la injusticia que provocan, por un lado, el ideal de imparcialidad; y, por el otro, modelos democráticos, como el deliberativo, basado en el interés. Con esta propuesta, se otorgaría un valor positivo a la(s) diferencia(s) y se generarían posibilidades de reconocimiento de las mismas, a través de la reflexión y la transformación de procedimientos y estilos comunicativos.

Para la autora, ${ }^{69}$ el modelo democrático basado en el interés, consistiría en procesos democráticos en los que las y los participantes deciden qué es lo que más convienen al mayor número de personas posible, mediante el registro de las preferencias individuales en el voto. De este modo, no se niega la diferencia, pero se ha de trascender para llegar a un consenso que beneficie a la mayoría por medio del debate político. Este modelo se basaría en la racionalidad, la validez de los argumentos y la igualdad de oportunidades para expresarse. Es decir, la base del modelo reside en una serie de procedimientos formales, que serían neutrales y universales para garantizar la deliberación democrática. En definitiva, estos modelos democráticos asumen, según Young, ${ }^{70}$ que existe una universalidad en la racionalidad y una unidad común.

El problema principal que se observaría con respecto al carácter excluyente de la universalidad, radicaría en emplear como únicos elementos de discusión democrática los argumentos razonados. Según Young "Su tendencia a restringir la discusión democrática a

\footnotetext{
${ }^{65}$ Ibidem.

${ }^{66}$ Young, La justicia y la política de la diferencia.

${ }^{67}$ Nussbaum, El ocultamiento de lo humano.

68 Young, La justicia y la política de la diferencia; Young, "La democracia y el otro".

${ }^{69}$ Young, La justicia y la política de la diferencia.

70 Young, "La democracia y el otro".
} 
meros argumentos trae implícitamente aparejados prejuicios culturales que pueden conducir a exclusiones de personas o grupos en la práctica". ${ }^{71}$

Por tanto, según Young, ${ }^{72}$ estos modelos políticos no tendrían en cuenta las diferencias particulares. Es decir, no entienden que existan diferentes voces o, mejor dicho, diferentes estilos discursivos. Como consecuencia de este mito (en palabras de Nussbaum) persiste la creencia de que todas las voces son escuchadas de la misma manera y que se les otorga a todas la misma credibilidad y estatus. Es decir, ambos modelos "fracasan en notar que el poder social que tiene capacidad de impedir que las personas sean iguales no sólo deriva de un factor de dependencia económica o dominación política sino también de un sentido internalizado del derecho a hablar o no hablar y de la devaluación sobre el estilo discursivo y elevación de los otros". ${ }^{73}$

Pero, ¿dónde reside la relevancia de los estilos discursivos? En el caso de la diversidad severa o que produce alteraciones en el habla, parece claro, no son escuchados porque no pueden comunicarse del modo político tradicional, es decir mediante el lenguaje hablado o escrito. Pero, más allá de esta característica, los estilos discursivos, comunicativos o del habla, son las estructuras comunicativas que surgen en la interacción cotidiana, la percepción de grupo y la interacción entre éstos. ${ }^{74}$ Cuestiones estrechamente relacionadas con la reproducción de la injusticia, tal y como se ha comentado anteriormente. Acudiendo al caso de las diferencias por género, la lingüista Deborah Tannen ha analizado los estilos comunicativos de hombres y mujeres como grupos sociales diferentes. Una diferente socialización generaría una diferente relación comunicativa. Por un lado, el lenguaje de las mujeres buscaría minimizar las diferencias, amistad o intimidad. Y, por el otro, el objetivo del de los hombres sería la conquista de un estatus e independencia. ${ }^{75}$ Tannen afirma "Aunque hayan nacido en el mismo barrio, en la misma calle o en la misma casa, los niños y las niñas crecen en distintos mundos de palabras. Las personas les hablan de un modo diferente y esperan y aceptan de ellos respuestas distintas". ${ }^{76}$

${ }^{71}$ Ibid., 43.

${ }^{72}$ Ibidem.

${ }^{73}$ Ibid., 44.

${ }^{74}$ Mariam Martínez-Bascuñán, Género, emancipación y diferencia(s). La teoría política de Iris Marion Young (Madrid: Plaza y Valdés, 2012), 206.

75 Deborah Tannen, Tú no me entiendes (Buenos Aires: Javier Vergara Ed, 1993). http://www.iesalboran.com/filosofia/tunomeentiendes.pdf.

${ }^{76}$ Ibid., 18. 
En función de la experiencia se defiende la independencia o la intimidad, por lo que las relaciones, conversaciones y escucha son diferentes. En el caso de las mujeres, cederían su posición de privilegio y tenderían a escuchar más en los intercambios lingüísticos. Atendiendo a este caso, puede afirmarse que la forma de expresarnos, escuchar y relacionarnos varía en función de nuestras experiencias como miembros de un grupo social. En el caso de Tannen, ${ }^{77}$ el de las mujeres versus el de los hombres, pero en el planteamiento de Young también es extensible a otros grupos minorizados como las personas negras o hispanas de EE.UU. ${ }^{78} \mathrm{Y}$, en el caso que nos ocupa, podríamos hablar también de las personas con discapacidad, ${ }^{79} \mathrm{y}$, especialmente, el de aquellas que dada su situación no pueden expresarse empleando discursos normalizados o, incluso, hablando o escribiendo.

Para contextualizar la relevancia de estos estudios en relación con la vulnerabilidad social, la injusticia y la opresión, deben ponerse en relación con la participación en los procesos democráticos, pero, también, con el espacio público, la elaboración de legislaciones o el debate social, planteados por Nussbaum. ${ }^{80}$ Ya que, entonces, se entiende que estos procesos no pueden considerarse universales, y mucho menos neutrales, dadas las diferencias en las experiencias y la escucha que se tiene de determinadas voces, como son algunas de las que hemos comentado cómo las mujeres, las personas con discapacidad o las personas negras o hispanas en EE.UU. Así pues, los grupos oprimidos verían denostada su palabra en pro de la de los grupos privilegiados, por medio de las normas de asertividad y confrontación, reforzando, a través de tales asunciones comunicativas, las injusticias. ${ }^{81}$ En este sentido, la propuesta de Nussbaum ${ }^{82}$ resulta necesaria, pero considerando el no caer en la falsa universalidad.

Atendiendo a esta cuestión, puede hablarse de que existe una jerarquización implícita de los estilos comunicativos que incide directamente en la participación política. ${ }^{83}$ Algunas de las afirmaciones como "los jóvenes no participan", "las mujeres no quieren tomar el poder que se les ofrece" o expresiones similares con respecto a grupos sociales

\footnotetext{
77 Ibidem.

78 Young, "La democracia y el otro".

${ }^{79}$ Aparicio, "Estigmatización, invisibilización".

${ }^{80}$ Nussbaum, El ocultamiento de lo humano.

${ }^{81}$ Young, "La democracia y el otro".

${ }^{82}$ Nussbaum, El ocultamiento de lo humano.

${ }^{83}$ Young, La justicia y la politica de la diferencia; Young, "La democracia y el otro".
} 
oprimidos se vincularía con un problema en el modelo político, que debe repensarse, además de la propuesta de Nussbaum, ${ }^{84}$ y vinculada a ella. En este sentido, resultaría positivo un cambio en la legislación, siempre y cuando para ello se escuchara, incluyendo a todas las personas, para lo que se precisa de ese cambio en el modelo participativo y la escucha. ${ }^{85}$ Autores como Jane Mansbridge ${ }^{86}$ y Amy Gutman, ${ }^{87}$ entre otros, refuerzan esta idea, mostrando obstáculos que encuentran los grupos oprimidos para su representación y participación en los procedimientos considerados democráticos. Gutman, ${ }^{88}$ llega un paso más allá, advirtiendo que algunos de estos procesos pueden incluso reforzar la exclusión y la injusticia, en lugar de evitarla, generando, además, una falsa ilusión de equidad y justicia social. Todos estos estudios, se basaban en que la diferencia provenía de la exigencia de ciertos estilos comunicativos concretos. En palabras de Young los grupos privilegiados están acostumbrados a tener autoridad mientras que otros grupos se sienten intimidados por las normas discursivas.

Por tal motivo, tienden a no hablar, o hablan sintiendo que aquellos que conducen este proceso encuentran desorganizadas estas intervenciones. Las normas de asertividad, combatividad y el respeto por las reglas de la competencia son silenciadores poderosos o evaluadores del discurso de aquellos grupos que se encuentran en una situación de diferencia cultural e inequidad. ${ }^{89}$

En este sentido, la autora apuesta por incluir nuevas formas comunicativas, más allá de la argumentación, en la deliberación: los saludos, la retórica y la narración. Con los saludos, Young se refiere a expresiones como "Buenos días" o "Nos vemos en un rato", y, también a los halagos o las sonrisas, todo ello como muestra de reconocimiento y apoyo. Por otro lado, la retórica, facilita la eliminación de la dicotomía razón-deseo propia del ideal de imparcialidad, conectando con la audiencia. Y, por último, la narración, entendida como vehículo de valores y significados culturales, que permite expresar nuestras experiencias y el efecto de las decisiones que se toman sobre las personas particulares. ${ }^{90}$

\footnotetext{
${ }^{84}$ Nussbaum, El ocultamiento de lo humano.

${ }^{85}$ Young, La justicia y la política de la diferencia.

${ }^{86}$ Jane J. Mansbridge, Beyond adversarial democracy (Chicago: The University of Chicago Press, 1980).

${ }^{87}$ Amy Gutman, Liberal equality (Cambridge: Cambridge University Press, 1980).

${ }^{88}$ Ibidem.

${ }^{89}$ Young, "La democracia y el otro", 45 y 46.

${ }^{90}$ Ibidem.
} 
A través de estas herramientas la autora sostiene que se transformaría la perspectiva de los y las participantes, ya que revela la parcialidad de mi experiencia, la situación de colectividad con personas diferentes e intereses diferentes, aunque iguales derechos; y, el incremento del conocimiento social mediante la escucha. ${ }^{91}$ Aunque se trata de una "reciprocidad asimétrica", 92 en tanto que las perspectivas son intransferibles dada nuestra experiencia previa, siendo, por tanto, un ejercicio de empatía y no de simpatía.

Pero, para llevar a cabo todo este proceso, más allá de las cuestiones planteadas por Nussbaum, ${ }^{93}$ debe incorporarse el concepto de inclusión, definido y entendido en profundidad, como condición necesaria para el entendimiento, la participación y la interacción entre grupos sociales. En este sentido, debe aclararse que "[1]a integración en la vida plena de la sociedad no debería implicar asimilación a las normas dominantes y abandono de la afiliación y cultura de grupo". ${ }^{94}$ Es decir, no basta con incluir a estos grupos en los procesos de participación y toma de decisiones, sino que es también necesario que puedan hacerlo empleando sus estilos discursivos, sus experiencias y formas de comunicarse. Por ejemplo, en el caso de las personas con discapacidad se deben adaptar estos procesos a sus necesidades, empleando lectura fácil, sistemas de comunicación aumentativa, braille o lengua de signos, entre otros mecanismos de apoyo. Un ejemplo sería el de la escasa normativa existente en lectura fácil, que limita el acceso de estas personas al conocimiento, debate y reivindicación en torno a sus derechos y los procesos sociales que les afectan.

Desde el punto de vista de Young, la inclusión sería la condición necesaria para la consecución de las medidas planteadas por Nussbaum, ${ }^{95}$ logrando a través de ella un espacio cívico público heterogéneo. Ésta, por tanto, sería participativa, ya que promueve la igualdad, rompiendo la dicotomía dentro-fuera y generando condiciones de no-dominación; y, transformadora, convirtiendo las diferencias en demandas políticas y medios para el entendimiento. Como señala Martínez-Bascuñán:

\footnotetext{
91 Ibidem.

${ }^{92}$ Ma. José Guerra Palmero, "Propuestas pragmáticas. Sobre el respeto moral y democracia comunicativa", Revista Laguna, núm. 9 (julio, 2001), 89 http://publica.webs.ull.es/upload/REV LAGUNA/092001/07 (Mar\%C3\%ADa Jos\%C3\%A9 Guerra Palmero).pdf.

${ }^{93}$ Nussbaum, El ocultamiento de lo humano.

${ }^{94}$ Young, La justicia y la política de la diferencia, 283.

95 Nussbaum, El ocultamiento de lo humano.
} 
La relajación en las condiciones de la participación, la incorporación de esos elementos que están más relacionados con los deseos y la experiencia corporal intrínsecos a la condición humana, permiten por sí solos la opción de un posibilismo transformativo porque proporcionan la inclusión de una pluralidad de "otros", y la opción de aprender y escuchar de las experiencias diferentes. ${ }^{96}$

Profundizando en la faceta transformadora de la inclusión, puede afirmarse que incrementa el conocimiento social, desde el momento previo a la consecución de acuerdos, mediante el intercambio de experiencias y perspectivas con otros grupos. A través de una escucha activa y consciente, y un espacio que favorezca la participación en igualdad, con un reconocimiento de los otros y sus diferencias, se llegaría a lo que Young, tomando la expresión de Hannah Arendt, denomina "pensamiento ampliado". Este nuevo pensamiento favorece mi entendimiento de la realidad de otros grupos, pero, también, apoya una reflexión y perspectiva ampliada de nuestra propia situación. Un ejemplo de ello, tomado de Young, es la lucha en contra de las sweatshops, donde se buscó concienciar de la situación y la responsabilidad conjunta por la justicia, en lugar de un boicot al método tradicional. ${ }^{97}$

En conclusión, según estos planteamientos, para lograr combatir la injusticia social es necesario concienciar en torno a la responsabilidad conjunta por la justicia. ${ }^{98}$ Para ello, no sólo se deben plantear modificaciones legislativas, sino que también deben complementarse con el replanteamiento del espacio público y la implementación de prácticas informales que lleven a un encuentro. ${ }^{99}$ Pero, para ello, se debe generar un espacio respetuoso con las diferencias e inclusivo, en el sentido de participación y transformación. En este sentido, debe considerarse que este espacio debe promover las condiciones de escucha y participación que favorezcan la no-dominación. ${ }^{100}$ Todo ello materializado en el caso de las personas con discapacidad en los medios de comunicación necesarios (lectura fácil, comunicación aumentativa, intérprete de lengua de signos, braille, etc.), sin tratarlos de forma devaluada y dirigidos directamente a estas personas en igualdad. ${ }^{101}$

\footnotetext{
${ }^{96}$ Martínez-Bascuñán, Género, emancipación y diferencia(s), 59.

${ }^{97}$ Iris M. Young, Responsabilidad por la justicia (Madrid: Morata, 2011).

98 Young, Responsabilidad por la justicia.

${ }^{99}$ Nussbaum, El ocultamiento de lo humano.

100 Young, La justicia y la politica de la diferencia.

101 Aparicio, "Estigmatización, invisibilización".
} 


\section{Conclusiones}

El paradigma de la diversidad funcional ha variado en los últimos años, apostando por un modelo social ratificado y apoyado por diversos documentos y posicionamientos institucionales y legales. Pero continúa existiendo una vulnerabilidad social y una discriminación para este grupo. En este sentido, los aspectos formales han generado espacios de participación y recursos de protección, pero tal y como muestran diferentes estudios el espacio público continúa siendo distante para este colectivo. Por ello, no basta con permitir o favorecer la participación de estas personas, sino que es necesario que sean escuchadas, ahí reside la importancia de conceptos como la inclusión, la justicia social, la opresión, el grupo social y, sobre todo la escucha, que propone la teoría de Iris Marion Young.

Atendiendo al concepto de injusticia de Young, ésta puede entenderse como todas las situaciones estructurales que impiden o dificultan la participación de las personas, generando una opresión. Para detectar estas situaciones la autora plantea cinco criterios o patologías sociales que "las cinco caras de la opresión": explotación, marginación, carencia de poder, imperialismo cultural y violencia. A partir de estos conceptos y el de grupo social, se reflexiona en torno a la(s) diferencia(s) y su percepción en el espacio público, manteniendo que se debe redefinir como un aspecto positivo y deseable, evitando que las diferencias se conviertan en desigualdades.

Esta injusticia y sus formas de opresión se han estudiado a su vez desde el campo de la psicología social, aplicado a la realidad de las personas con discapacidad. En este campo se parte de la noción de identidad social y de grupo, entendida como una creación cultural. A partir de ahí, se habla de esquemas mentales que permiten entender más rápidamente la sociedad, pero que, en la cultura actual, generan creencias (estereotipos), valoraciones (prejuicios) y acciones (discriminación) peyorativos hacía la discapacidad. Estas valoraciones están basadas en una tradición médica donde hay una valoración peyorativa de la discapacidad, entendiendo ésta como una anomalía o disfunción corporal. Desde la perspectiva del biopoder de Foucault, esta visión, que se basa en una falsa naturalización de esa infravaloración, serviría para controlar a determinados grupos sociales. En este caso, el de la diversidad funcional. Lo cual no sólo generaría injusticias, sino que, además, generaría una vulnerabilidad y afectación en la subjetividad y el desarrollo de estas personas. 
Para combatir esta situación, Young desarrolla una crítica a la universalidad y la neutralidad y el ideal de imparcialidad, propia del espacio público actual. A través de esta crítica, trata de evidenciar que las voces de los grupos privilegiados se consideran neutrales, privilegiando sus estilos discursivos e infravalorando o eliminando de los espacios de participación públicos frente a los de grupos sociales oprimidos, como los de las personas en situación de discapacidad. En este sentido, no usar medios de comunicación aumentativa y alternativa, intérpretes de lengua de signos o sistema Braille, entre otros, sería un ejemplo de opresión. Pero también lo sería, el obligar a seguir unos estilos discursivos formalmente aceptados a los que determinadas personas no pueden acceder, como es el caso de personas con dificultades del habla o la cognición; o, simplemente, obviar de la participación, aquellos discursos vinculados a las vivencias, percepciones, sentimientos y experiencias vividas. De este modo, aunque participarán, sólo serían escuchados grupos privilegiados, que no abarcarían a la totalidad de las personas, ni mucho menos a la totalidad de las personas con discapacidad.

Para lograr combatir las injusticias sociales en estos términos se plantea la necesidad de ampliar la participación y la deliberación en el espacio público, favoreciendo que no sólo se pueda hablar, sino que pueda hacerse en los propios términos de cada grupo social, lo que se denominaría inclusión. Ésta, sumada a una escucha activa, nos permite transformar las creencias (estereotipos), valoraciones (prejuicios) y, por tanto, acciones (discriminación) de quienes participan en una discusión, deliberación o diálogo.

En este sentido, propuestas como la de Nussbaum se complementarían para eliminar las injusticias sociales y dar cabida a la diversidad de las personas, más allá de los aspectos formales, logrando modificar el espacio público de forma complementaria. En este sentido, se pone de manifiesto que los impulsos formales por la lucha de las injusticias deben ser complementado desde la modificación en el espacio público, para lo cual la inclusión y la escucha son una pieza clave. En el caso de la diversidad funcional, esta cuestión sería clave para suprimir patologías como la estigmatización, la cosificación o la invisibilización, recogidas por Aparicio, que suponen una vulneración de su reconocimiento como personas y parte de la sociedad, afectando a su subjetividad.

Pese a la apertura a diferentes grupos que aborda esta propuesta, quedarían líneas abiertas como qué estructuras, metodologías o intervenciones sería necesario crear para 
lograr esta propuesta inclusiva que propone Young, y, más aún, cómo lograrlo en un mundo globalizado como el actual. 


\section{Bibliografía}

Abad Miguélez, Begoña. "La Producción Socio-Institucional de Sufrimiento Social”. RIMCIS - International and Multidisciplinary Journal of Social Sciences 5, núm. 1 (2016): 1-25. http://doi.org/10.17583/rimcis.2016.1802.

Aparicio, Manuel. "Estigmatización, invisibilización y cosificación de las personas con diversidad funcional. Una aproximación desde la justicia como reconocimiento de Axel Honneth”. Revista Española de Discapacidad 4, núm. I (2016): 177-190. https://www.cedd.net/redis/index.php/redis/article/view/245.

European Commission. Special Eurobarometer 493: Discrimination in the EU (including LGBTI), Bruselas: Directorate-General for Communication, 2019, http://data.europa.eu/euodp/en/data/dataset/S2251_91_4_493_ENG.

Fernández, Anna M. "Prejuicios y estereotipos. Refranes, chistes y acertijos, reproductores y transgresores”. Revista de Antropología Experimental, núm. 11 (2011): 317-328. https://revistaselectronicas.ujaen.es/index.php/rae/article/view/1932.

Foucault, Michel. El nacimiento de la clínica. Madrid: Siglo XXI, 2001.

Guerra Palmero, Ma. José. "Presentación. Iris Marion Young, la pensadora de las injusticias estructurales y de la responsabilidad política”. Enrahonar. Quaderns de Filosofía, núm. 51 (2013): 5-12. http://revistes.uab.cat/enrahonar/article/view/v51guerra/pdf-es.

Guerra Palmero, Ma. José. "Propuestas pragmáticas. Sobre el respeto moral y democracia comunicativa". Revista Laguna, núm. 9 (julio 2001): 87-98, http://publica.webs.ull.es/upload/REV LAGUNA/09 2001/07 (Mar\%C3\%ADa Jos\%C3\%A9 Guerra Palmero).pdf.

Gutman, Amy. Liberal equality. Cambridge: Cambridge University Press, 1980.

Jiménez, Antonio. Personas con discapacidad y discriminación múltiple en España: situación y propuestas, Madrid: Observatorio Estatal de la Discapacidad, 2017. https://www.observatoriodeladiscapacidad.info/wpcontent/uploads/2017/12/DISCR IMINACION-MULTIPLE-OED.pdf.

Le Breton, David. Sociología del cuerpo. Buenos Aires: Ed. Nueva Visión, 2008.

Lu, Junfei, Wesley B. Webber, Devon Romero y Chris Chirino. "Changing Attitudes Toward People with Disabilities Using Public Media: An Experimental Study". 
Rehabilitation Counseling Bulletin 61, núm. 3 (2017): 175-186. http://dx.doi.org/10.1177/0034355217700820.

Madrid, Antonio. La politica y la justicia del sufrimiento. Madrid: Trotta, 2010.

Mansbridge, Jane J. Beyond adversarial democracy. Chicago: The University of Chicago Press, 1980.

Martínez-Bascuñán, Mariam. Género, emancipación y diferencia(s). La teoría política de Iris Marion Young. Madrid: Plaza y Valdés, 2012.

Mira-Aladrén, M. (2015). "La escucha en la democracia comunicativa de Iris Young". Trabajo de Fin de Grado en Filosofía bajo la dirección de Ma. Aránzazu Hernández Piñero. Facultad de Filosofía y Letras de la Universidad de Zaragoza.

Mitra, Sophie, y Tom Shakespeare. "Remodeling the ICF". Disability and Health Journal 12, núm. 3 (julio, 2019): 337-339. https://doi.org/10.1016/j.dhjo.2019.01.008.

Muñoz, Silvia (coord.). Cuadernos de Buenas Prácticas. Las personas con discapacidad intelectual en la función pública: Informe sobre situación, recomendaciones y apoyos tecnológicos. Madrid: Plena Inclusión, 2018. https://www.plenainclusion.org/publicaciones/buscador/las-personas-condiscapacidad-intelectual-en-la-funcion-publica-informe-sobre-situacionrecomendaciones-y-apoyos-tecnologicos/.

Nussbaum, Martha C. El ocultamiento de lo humano: repugnancia, vergüenza y ley. Madrid: Katz Barpal, 2006.

Paluck, Elizabeth Levy, Seth A. Green y Donald P. Green. "The contact hypothesis reevaluated". Behavioural Public Policy, núm. 3.2 (2019): 129-158. http://dx.doi.org/10.2139/ssrn.2973474.

Pindado, Fernando. Hacia una única catalogación de los derechos fundamentales -los derechos económicos, sociales y culturales de las personas con discapacidad como derechos fundamentales-. Madrid: Ediciones Cinca, 2015.

Ruíz Quiroga, Patricia M. "La evolución de la atención a la diversidad del alumnado de educación primaria a lo largo de la historia". Temas para la educación, revista digital para profesionales de la enseñanza, núm. 8 (2010): 1-15. https://feandalucia.ccoo.es/docu/p5sd7241.pdf. 
Sánchez Criado, Tomás. Cuerpo, discapacidad, vejez: calles para todos. Barcelona: Material de la UOC, Introducción a las Ciencias Sociales, 2019.

Shotter, Jhon, y Kenneth J. Gergen. Texts of identity. California: Sage Publications, 1989.

Solé Blanch, Jordi, y Asun Pié Balaguer (coords.). Políticas del sufrimiento y la vulnerabilidad. Madrid: Icaria, 2018.

Tajfel, Henri. "La catégorisation sociale". En Introduction à la psychologie sociale, vol. 1. Ed. Serge Moscovici. París: Larousse, 1972.

Tannen, Deborah. Tú no me entiendes. Buenos Aires: Javier Vergara Ed, 1993.

Young, Iris M. “La democracia y ‘el otro’: más allá de la democracia deliberativa”, trad. de Lelia Mooney Sirotinsky. Revista Jurídica de la Universidad de Palermo, Año 5, $\begin{array}{llll}\text { núm. } & 1 & \text { (agosto, } & \text { 2000): }\end{array}$

http://www.palermo.edu/derecho/publicaciones/pdfs/revista_juridica/n5N12000/051Juridica03.pdf.

Young, Iris Marion. La justicia y la política de la diferencia. Madrid: Cátedra, 2000.

Young, Iris Marion. Responsabilidad por la justicia. Madrid: Morata, 2011. 